\title{
NOTE
}

\section{Effect of Streptozotocin Administration on Somatostatin Content of Pancreas and Hypothalamus in Rats}

\author{
Hideichi MAKINO ${ }^{1}$, Azuma KANATSUKA ${ }^{1}$, YasuHisa MATSUSHIMA ${ }^{1}$, \\ Masahiro YAMAMOTO ${ }^{1}$, AKIRA KUMAGAI ${ }^{1}$ AND Noboru YANAIHARA ${ }^{2}$ \\ ${ }^{1}$ Second Department of Internal Medicine, Chiba University School \\ of Medicine, Chiba 280 and ${ }^{2}$ Laboratory of Bioorganic Chemistry, \\ Shizuoka College of Pharmacy, Shizuoka 422, Japan
}

\section{Synopsis}

A radioimmunoassay (RIA) method for somatostatin (SRIF) utilizing rabbit antiserum against synthetic SRIF coupled with human serum $\alpha$-globulin is described. Synthetic $\mathrm{N}^{\alpha}$-tyrosylated SRIF was labelled with ${ }^{125} \mathrm{I}$ using the lactoperoxidase method and purified on a Sephadex G-10 column. This assay system was highly specific for SRIF and did not cross-react with hypothalamic trophic hormones, pituitary trophic hormones or gastrointestinal hormones.

The effect of streptozotocin induced diabetes on the SRIF content was examined in the pancreas, the pancreatic islets, as well as the hypothalamus of rats. SRIF content in both the pancreas and islets of the diabetic rats was shown by RIA to have significantly increased. However, content in the hypothalamus of the diabetic rats did not differ from that of the control. The physiological and pathophysiological significance of the SRIF changes remains to be determined.

Somatostatin (SRIF) was isolated from the ovine hypothalamic tissue and the structure was characterized as a cyclic tetradecapeptide (Brazeau et al., 1973). Radioimmunoassay (RIA) measurement of tissue extracts and immunohistochemical techniques have revealed an unexpectedly wide anatomical distribution of SRIF, especially in the D cells of the pancreatic islets (Arimura et al., 1975; Hökfelt et al., 1975; Dubois, 1975).

Furthermore, SRIF inhibits not only the release of growth hormone from the pituitary but also the release of insulin and glucagon by its direct action on their respective secretory cells (Alberti et al., 1973; Koerker et al., 1974). More recent data using immunohistochemical techniques and RIA suggest that streptozotocin-induced diabetes may result in the hyperplasia of

\footnotetext{
Received for publication December 27, 1976.
}

the $D$ cells and the increased SRIF content of the islets, but they still remain problems to be solved. (Orci et al., 1976; Patel et al., 1976).

The present study was undertaken to establish a specific RIA method of SRIF and to examine the effect of streptozotocininduced diabetes on the SRIF content in the pancreas, pancreatic islets and the hypothalamus.

\section{Materials and Methods}

Male rats of the Sprague-Dawley strain weighing $180-240 \mathrm{~g}$ were used in the present study. The animals were maintained at $24^{\circ} \mathrm{C}$ with controlled lighting (lights on $07: 00-19: 00 \mathrm{hr}$ ) and given free access to a laboratory chow (purchased from Oriental Yeast Co., Tokyo) and tap water throughout the experiments.

Twenty-two rats were given streptozotocin, 65 $\mathrm{mg} / \mathrm{kg}$, (lot No. 60140, gift from the Upjohn Inter- 
national Inc., Kalamazoo, Mich.) intravenously and sixteen control rats were given only $0.2 \mathrm{ml}$ of $0.1 \mathrm{M}$ citrate buffer solution ( $\mathrm{pH} 4.5$ ) intravenously.

Four weeks following the injection, seventeen streptozotocin-injected rats and ten control rats which had all fasted for about $12 \mathrm{hr}$, were weighed and decapitated. Trunk blood was collected for glucose measurement (Technicon glucose analyzer). The pancreas was quickly removed, weighed and homogenized in $10 \mathrm{~m} l$ chilled $2 \mathrm{~N}$ acetic acid. Simultaneously the hypothalamus was removed as described by Brownstein et al. (1975), weighed and homogenized in $1 \mathrm{~m} l$ chilled $2 \mathrm{~N}$ acetic acid.

Four weeks following the injection, pancreatic islets of five streptozotocin-diabetic rats and six control rats were obtained from each of the animals using collagenase digestion with a modification of the technique of Lacy and Kostianovsky (1967). Groups of five same-sized islets were separately extracted in $1 \mathrm{ml} 2 \mathrm{~N}$ acetic acid. These extracts were then suspended in boiling water for ten min, centrifuged at $12,000 \mathrm{rpm}$ for $30 \mathrm{~min}$, then lyophylized and kept in a refrigerator until assay.

SRIF was determined by RIA utilizing a rabbit antiserum obtained following immunization with synthetic SRIF which had been conjugated with human serum $\alpha$-globulin (Wako Chemicals Ltd., Tokyo) using glutaraldehyde according to the method of Arimura et al. (1975). Synthetic $\mathrm{N}^{\alpha}$-tyrosylated SRIF was labelled with ${ }^{125}$ I using the lactoperoxidase method and purified on a Sephadex G-10 column, $0.8 \times 20 \mathrm{~cm}$, eluted with $1 \mathrm{~N}$ acetic acid. An aliquot of each fraction was incubated with the antiserum diluted at $1: 84,000$ for $24 \mathrm{hr}$ and the bound and free hormone were separated by dextran-coated charcoal, The remaining assay methods were the same as those described by Arimura et al. (1975).

Synthetic $\mathbf{N}^{\alpha}$-tyrosylated SRIF, vasoactive intestinal peptide (VIP) and secretin were synthesized in Dr. Yanaihara's laboratory. hGH (HS 2160 E), hFSH (LER 907), hLH (LER 907), hTSH, porcine prolactin, rat $\mathrm{GH}$ (NIAMD-rat GH-RP-I), rat prolactin (NIAMD-rat prolactin-RP-I), rat FSH (NIAMD-rat FSH-RP-I), rat LH (NIAMD-rat LH-RP-I), and rat TSH (NIAMD-rat TSH-RP-I) were kindly supplied by NIAMDD. Oxytocin was a donation of Sandoz Ltd. Synthetic SRIF used as the standard, substance $\mathrm{P}$, neurotensin, TRH, LH- RH, and the MSH release inhibiting factor were purchased from the Peptide Institute, Protein Research Foundation, Osaka. Gastrin and lysine vasopressin were purchased from Sigma Co. and $\alpha^{1-24}$ ACTH from Daiichi Chemical Co., Tokyo.

Statistical comparison among all groups was carried out using the Student's $t$ test.
June 1977

\section{Results}

An example of the iodinated $\mathrm{N}^{\alpha}$-tyrosylated SRIF was depicted in Fig. 1. The first peak was antibody-boundable and used for RIA, and the typical standard curve of SRIF was shown in Fig. 2. The sensitivity of the assay varied from $7.8 \mathrm{pg}$ to $15.6 \mathrm{pg}$ with a final antiserum dilution of $1: 84,000$, with the tracer having a specific activity of $100 \mu \mathrm{Ci} / \mu \mathrm{g}$.

The displacement curve of extracts from the pancreas and the hypothalamus was shown to be parallel to the standard curve (Fig. 2). The recovery of standard SRIF added to the pancreatic extract was over $90 \%$. The intra-assay variation was $12 \%$ $(\mathrm{N}=15)$, while the interassay variation was $18 \%(\mathrm{~N}=8)$.

This antiserum was highly specific for SRIF with negligible or no cross-reactivity with insulin, glucagon, gastrin, VIP, secretin, substance $\mathrm{P}$, neurotensin, TRH, LH-RH, MSH release inhibiting factor, lysine vasopressin, oxytocin, ACTH, hGH, hFSH, hLH, $\mathrm{hTSH}$, porcine prolactin, rat $\mathrm{GH}$, rat $\mathrm{FSH}$, rat $\mathrm{LH}$, rat $\mathrm{TSH}$, and rat prolactin.

Despite being of comparable age, the diabetic rats weighed less than the controlled rats $(232 \pm 14 \mathrm{~g}$ os $311 \pm 12 \mathrm{~g}$, mean \pm SEM, $\mathrm{p}<0.001)$ and the streptozotocininjected non-diabetic rats $(285 \pm 11 \mathrm{~g}, \mathrm{p}<$ $0.01)$. As for the mean fasted blood glucose level, the diabetic rats showed $179 \pm 22 \mathrm{mg} /$ $\mathrm{d} l$, compared to the control level of $70 \pm 1$ $\mathrm{mg} / \mathrm{d} l, \mathrm{p}<0.001$ and the level of the streptozotocin injected non-diabetic rats of $79 \pm 2 \mathrm{mg} / \mathrm{d} l, \mathrm{p}<0.01$.

A significant increase of the pancreatic SRIF content in the diabetic rats was found in the total organ $(\mathrm{p}<0.01)$ or in its concentration $(\mathrm{p}<0.001)$ (Fig. 3). Furthermore, the SRIF content in the islets was significantly increased in the diabetic rats, $\mathrm{p}<$ 0.01 (Fig. 4). However, the pancreatic 


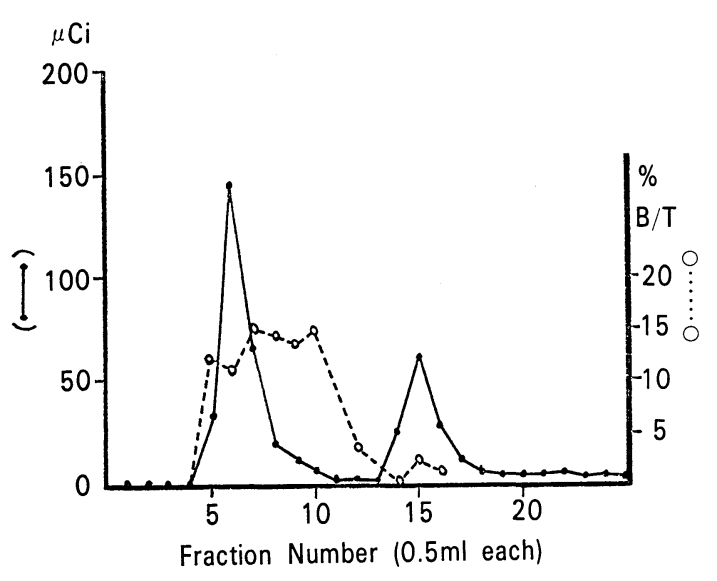

Fig. 1. Elution pattern of ${ }^{125} \mathrm{I}-\mathrm{N}^{\alpha}$-tyrosylated SRIF on Sephadex G-10 column with $1 \mathrm{~N}$ acetic acid. $0-0$ radioactivity; $0 \cdots \cdots .0$ binding activity to the antiserum diluted at $1: 84,000$ and incubated with an aliquot of each fraction for $24 \mathrm{hr}$. First peak contained labelled products with greatest immunoreactivity. Second peak corresponded to free iodide.

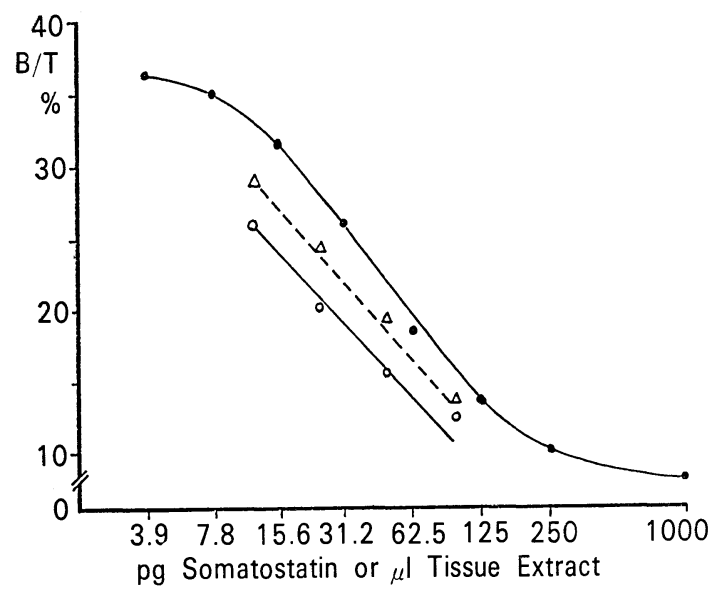

Fig. 2. Semi-logarithmic plot comparing competitive inhibition of ${ }^{125} \mathrm{I}-\mathrm{N}^{\alpha}$-tyrosylated SRIF binding to antibody by synthetic SRIF (closed circles), pancreatic extract (open circles), and hypothalamic extract (closed triangles). Anti-serum No. III-16 was used at $1: 84,000$ dilution. The reaction mixture was incubated at $4^{\circ} \mathrm{C}$ for $48 \mathrm{hr}$ and the bound and free hormone were separated by dextrancoated charcoal. Nonspecific binding after treatment with dextan-coated charcoal was $6 \%$.

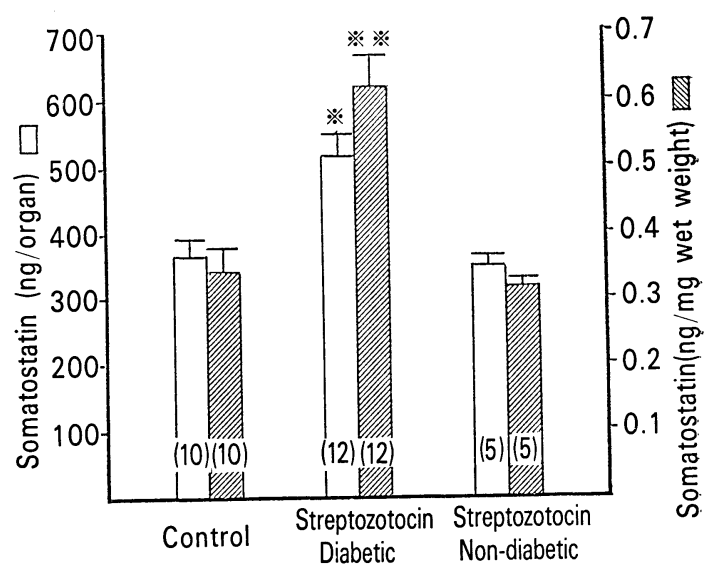

Fig. 3. Effect of streptozotocin administration on SRIF content in the rat pancreas. The male rats were given $65 \mathrm{mg} / \mathrm{kg}$ of streptozotocin intravenously 4 weeks prior to sacrifice. Standard errors are given by vertical lines. The figure in parentheses refers to the number of glands assayed in each experiment. ${ }^{*} \mathrm{p}<0.01, * * \mathrm{p}<0.001$

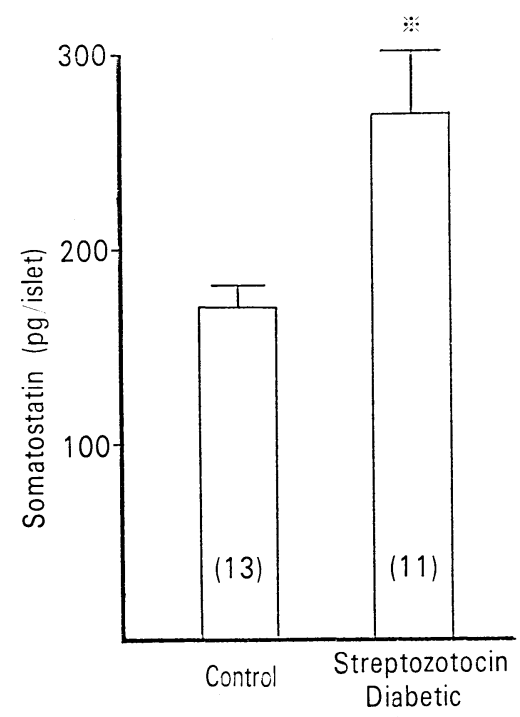

Fig. 4. Effect of streptozotocin administration on SRIF content in the pancreatic islets of the rat. The figure in parentheses refers to the number of five islet groups assayed in the experiment. Standard errors are given by vertical lines. ${ }^{*} \mathrm{p}<0.01$ 


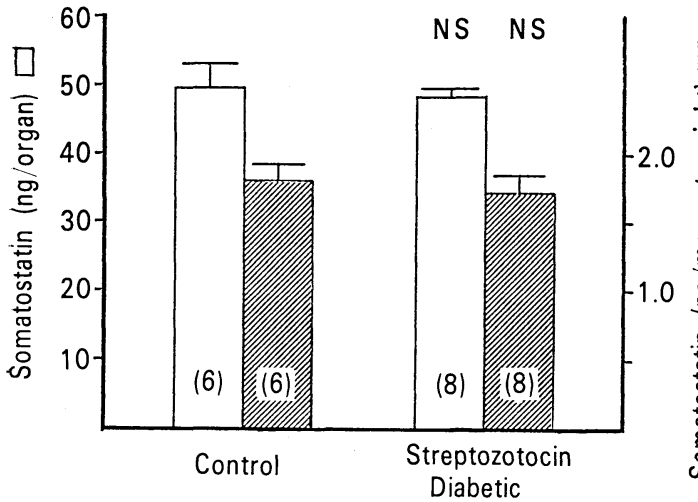

Fig. 5. Effect of streptozotocin administration on SRIF content in the rat hypothalamus. Standard errors are given by vertical lines. The figure in parentheses refers to the number of glands assayed in each experiment.

SRIF content of the streptozotocin injected non-diabetic rats did not differ from that of the controls (Fig. 3).

Figure 5 illustrates that no change had taken place in the hypothalamic SRIF content of the diabetic rats.

\section{Discussion}

It is shown in this paper that antisera against systhetic SRIF can be generated in rabbits by injecting them with the peptide coupling to human serum $\alpha$-globulin. Using these antisera at the final dilution of $1: 84,000$, a RIA method was developed, which allowed the detection of as little as $7.8 \mathrm{pg}$ of SRIF. Furthermore, this method presented a remarkable specificity.

No cross-reaction was observed either with hypothalamic and pituitary trophic hormones or with gastrointestinal hormones. In addition, hypothalamic and pancreatic extracts from rats showed a dilutional curve parallel to that of synthetic SRIF, indicating immunological identity between them. In using an immunohistochemical technique with the antiserum used in the present study, we have observed that SRIF is contained in the median eminence as well as in the D cells of the Langerhans islets of the rat (submitted for publication).

By employing this RIA system, we showed that the SRIF content of both the pancreas and islet of diabetic rats was increased significantly. These findings correlate closely with the recent data regarding diabetic rats showing a marked increase in the total number of SRIF-producing cells per pancreas (Orci et al., 1976) as well as an increased content of SRIF in islets (Patel and Weir, 1976).

It is plausible that streptozotocin might have a direct effect on SRIF-containing cells, as it was observed that pancreatic SRIF content from streptozotocin injected non-diabetic rats did not vary from that from the control. It is possible that hyperglycemia or other metabolic derangement had a direct stimulatory effect on SRIFproducing cells. Yet another possibility is that hypoinsulinemia or hyperglucagonemia thus produced exerted compensatory effect on SRIF-producing cells.

Although it has been reported that abnormal GH response was observed in the diabetic patient (Matsushima et al., 1977; Nakagawa et al., 1970), the data obtained here demonstrate no change of the hypothalamic SRIF content of the diabetic rats.

As the relationship between SRIF content and secretion is not clear, further studies into this problem will be necessary in order to identify the pathophysiological significance of the SRIF changes. 


\section{Acknowledgement}

We are grateful to NIAMDD for the donations of hGH, hLH, hFSH, hTSH, rat GH, rat prolactin, rat $\mathrm{LH}$, rat $\mathrm{FSH}$, rat $\mathrm{TSH}$ and porcine prolactin, Upjohn International Inc. for the streptozotocin and Sandoz Ltd. for the oxytocin.

Also we wish to express our gratitude to Miss Haruko Sato, Shizuoka College of Pharmacy, for her kind advice.

\section{References}

Alberti, K. G. M., N. J. Christensen, S. E. Christensen, A. P. Hansen, J. Iversen, K. Lundbrek, K. Seyer-Hansen, H. Фyskov (1973). Lancet 2, 1299.

Arimura, A., H. Sato, O. H. Coy and A. V. Schally (1975). Proc. Soc. Exp. Biol. Med. 148, 784.

Brazeau, R., W. Vale, R. Burgus, N. Ling, M.
Butcher, J. Rivier and R. Guillemin. (1973). Science $179,77$.

Brownstein, M., A. Arimura, H. Sato, A. V. Schally and J. S. Kizer (1975). Endocrinology 96, 1456.

Dubois, M. P. (1975). Proc. Nat. Acad. Sci. U.S.A. 72,1340

Hökfelt, T., S. Efendic, C. Hellerstrom, O. Johansson, R. Luft and A. Arimura (1975). Acta Endocrinol. (Suppl.) 200, 5.

Koerker, J., W. Ruch, E. Chideckel, J. Palmer, C. J. Goodner, J. Ensinck and C. C. Gale (1974). Science 184, 482.

Lacy, P. E. and M. Kostianovsky (1967). Diabetes 16, 35 .

Matsushima, Y., H. Makino, A. Kanatsuka, M. Yamamoto and A. Kumagai (1977). Folia Endocr. Japon. in press (In Japanese)

Nakagawa, K. and R. Iriyama (1970). J. Japan Diab. Soc. 13, 182 (In Japanese)

Orci, L., D. Baetens, C. Buffener, M. Amherdt, M. Ravazzola, P. Studer, F. Malaisse-Lagae and R. H. Unger (1976). Proc. Nat. Acad. Sci.U.S.A. 73, 1338.

Patel, Y. C. and G. C. Weir (1976). Clin. Endocrinol. 5, 191. 